\title{
Un mundo real que no podemos ignorar, el caso de Rosario Tijeras
}

\author{
A real world we cannot ignore, the case of Rosario Tijeras
}

\section{Resumen}

Este artículo está basado en la investigación "Postulaciones políticas en la novela colombiana del siglo XIX” de la Universidad Cooperativa de Colombia, sede Bucaramanga, 2009. En particular, el objeto de esta investigación es la obra Rosario Tijeras del escritor colombiano Jorge Franco Ramos, quien se ha inspirado desde el rol femenino para contarnos una realidad vivida en su ciudad natal, Medellín.

Esta cruda realidad se asemeja a la vivida por muchos jóvenes colombianos, hecho que resulta significativo para utilizar dicha novela como elemento principal de una herramienta pedagógica novedosa que pretende llevar este tipo de lectura al aula de clase, y observar cómo esta clase de novelas promueve y genera en los estudiantes nuevos hábitos de lectura

Palabras clave

Narcotráfico, prostitución, sicariato, violencia.

\section{Abstract}

This article is based on the research "Political proposals in the nineteenth century Colombian novel" of Universidad Cooperativa de Colombia, Bucaramanga, 2009. In particular, the purpose of this research is Rosario Tijeras written by the Colombian author Jorge Franco Ramos, who took inspiration from the female role for telling us about a reality of his hometown Medellin.

This harsh reality, which is similar to that experienced by many Colombian young people, makes this novel significant to be used as the main element of a new educational tool which aims to bring this kind of readings into the classroom and see how these kinds of texts generate new reading habits in the students.

Keywords Drug trafficking, prostitution, killings, violence.
Andrea-del Pilar Vega*

Jessica Archila**;

Erika-Juliana Villamizar ${ }^{* * *}$

Docente que avala el artículo:

Jairo Castro Neira ${ }^{\text {***** }}$

Recibido: 4 de marzo del 2011

Aprobado: 18 de abril del 2011

Cómo citar este artículo: Vega, Andrea-de Pilar; Archila, Jessica y Villamizar, ErikaJuliana (2011), "Un mundo real que no podemos ignorar, el caso de Rosario Tijeras", en Rastros Rostros, vol. 13, núm. 25, pp. 71-73.

Estudiante de Licenciatura en Educación Básica con énfasis en Humanidades, Lengua Castellana e Inglés de la Universidad Cooperativa de Colombia, sede Bucaramanga. Correos electrónicos: andreadelpilarvega@campusucc. edu.co,pilaricavs@hotmail.com

*: Estudiante de Licenciatura en Educación Básica con énfasis en Humanidades, Lengua Castellana e Inglés de la Universidad Cooperativa de Colombia, sede Bucaramanga. Correos electrónicos: jessica.archila@campusucc.edu.co, vacatall12@hotmail.com

*** Estudiante de Licenciatura en Educación Básica con énfasis en Humanidades, Lengua Castellana e Inglés de la Universidad Cooperativa de Colombia, sede Bucaramanga. Correos electrónicos: erika.villamizar@campusucc.edu. co, erjuvisu@hotmail.com

**** Licenciado en Idiomas de la Universidad Industrial de Santander. Magíster en Semiótica (Tesista) de la Universidad Industrial de Santander. Docente de la Universidad Cooperativa de Colombia, sede Bucaramanga. Correo electrónico:jairo.castro@campusucc.edu.co 


\section{Introducción}

E le cuestan la vida. 1 presente artículo forma parte de los resultados de la investigación titulada "Postulaciones políticas en Colombia del siglo XX", que en su fase final abarcó un corpus de novelas correspondientes a la literatura de la violencia Colombiana durante la última mitad del siglo XX, y particularmente de la novela del escritor Jorge Franco Ramos, Rosario Tijeras.

La novela cuenta, a través de la protagonista Rosario cómo se vivió la violencia urbana en Medellín entre los años ochenta y noventa. Desde muy niña sufrió los rigores de la violencia: abusada por su padrastro, incomprendida por su madre y echada de su casa a muy corta edad, termina involucrada en la prostitución y el narcotráfico, que finalmente

Esta investigación se divide en tres capítulos, los cuales comprenden los espacios de experiencia, el análisis literario y la propuesta pedagógica. Los espacios de experiencia hacen referencia al autor, a las motivaciones que tuvo para escribir la obra, para crear sus personajes. El segundo capítulo lo constituye un análisis literario de la obra, y el tercero, la propuesta pedagógica.

El referente teórico a partir del cual se desarrolló la investigación fue la teoría de la triple mímesis de Paul Ricoeur, planteada en su obra Tiempo y narración (1995), la cual busca un nexo entre la acción vivida en el pasado y el tiempo presente. Por otra parte, se plantea un vínculo entre el presente, el pasado y las posibilidades de futuro.

\section{Desarrollo}

Después de hacer la lectura de la novela de Franco, fue necesario hacer una acercamiento a la historia de Colombia de la última mitad del siglo XX, en particular la que tuvo que ver con los carteles de narcotrafico y la violencia, que desarrollaron líderes mafiosos como Pablo Escobar y los hermanos Rodrigues Orejuela, entre otros.
Teniendo en cuenta que la mímesis l y la mímesis lll, son "el antes" y "el después" de la obra literaria, Ricoeur (1995) se propone demostrar que la mímesis ll posee la facultad de mediación entre el antes y el después del texto.

Los espacios de experiencia del autor colombiano Jorge Franco, nacido en Medellín en 1962, hablan de las motivaciones que tuvo para escribir su novela Rosario Tijeras, una obra que poco o casi nada tiene que ver con su personalidad, ya que se considera una persona tímida y alejada de este tipo de sociedad. En entrevista concedida a la revista Rabo de Ají (2000) cuenta que:

La historia tuvo su primer latido cuando leí una tesis de la facultad de Psicología de la Universidad de Antioquia, que trataba el tema de la religiosidad y el sicariato. Allí encontré unos testimonios conmovedores de unas niñas metidas en pandillas de sicarios, y algunas de ellas ya cargaban varios muertos encima. En ese momento creí que ahí había una historia para contar. Comencé a investigar, a buscar todo lo que hubiera sobre el tema, pero el dilema era cómo contar una historia de ficción, cuando nuestra realidad y la de estos muchachos, es tan absurda e inverosímil que parece ella misma una historia de ficción. Entonces decidí no basar el personaje en ningún testimonio en particular, sino que comencé a darle vida a un personaje literario con una historia propia. También eché mano de la historia de amor, y del mundo femenino, que ya había trabajado en mis libros anteriores. Todo el proceso de escritura me tomó alrededor de dos años.

En el análisis literario de la obra Rosario Tijeras, se trabajó el problema del espacio, en el que se describen sus espacios de vida como "la parte de la ciudad que le tocó a Rosario me impresionó tanto como a ella la parte mía con la diferencia de que yo no pude compararla con ningún Miami ni con ningún otro sitio que conociera. Por si no sabías esto también es Medellín me dijo el día que me tocó acompañarla" (Franco, 1999, pp. 40-41). Esta ubicación del tema en el espacio permite al lector tener un referente claro de donde se desarrolló la historia. 
En cuanto al tema, éste es independiente de si el autor quiere hacer su obra basada en sucesos reales o ficticios y, aunque en este caso son hechos fundamentados en casos reales, los nombres y los hechos narrados son el producto de su imaginación. Jorge Franco conocía muy de cerca el tema porque se crió en Medellín y porque dedicó buena parte de su trabajo al estudio del sicariato, de la prostitución infantil, del amor y el mundo femenino. La investigación hecha por el autor creó en él un gran interés por revelar lo que sucedía, disponiéndose así a contar en la historia el fondo de esa realidad. A través de Rosario Tijeras quiso representar cada una de las historias que escuchó en los diálogos que mantuvo con las niñas metidas en ese sistema.

La propuesta pedagógica tiene como objetivo principal trabajar dos áreas, lengua castellana y ciencias sociales, a partir de los fundamentos teóricos de la naturaleza de la literatura y su pedagogía, desarrollados por Alfonso Cárdenas Páez (2004).

El trabajo de investigación, finalmente, desarrolla una propuesta pedagógica dirigida a los estudiantes de décimo grado de educación básica para que, a partir de una obra literaria como Rosario Tijeras, reconozcan los conflictos de la sociedad en la que actúan y tengan la posibilidad de plantear alternativas de solución produciendo textos argumentativos sobre diferentes problemas sociales de Colombia durante la última mitad del siglo XX.

Los talleres de lecto-escritura permitirán que los estudiantes disfruten de la lectura de la obra literaria Rosario Tijeras, y que desarrollen un pensamiento crítico elaborando textos argumentativos. Este ejercicio pretende mostrar tres momentos del proyecto de aula: el diseño de talleres, su aplicación y la evaluación de éstos.

\section{Resultados}

La propuesta pedagógica se constituye en el principal resultado del proceso de investigación. De poco serviría que se trabajaran obras literarias en una escuela de formación de maestros, si no se buscara su relación con el trabajo profesional para el que se están preparando sus estudiantes. La literatura comprometida con la realidad es una de las mejores fuentes de formación del pensamiento crítico y se constituye en mediadora entre el desarrollo de estructuras lingüísticas elevadas y la producción de textos académicos.

\section{Conclusiones}

Las posibilidades que tiene la literatura como mediadora de procesos en la escuela son innumerables. La principal, claro está, es su función estética, la posibilidad que se tiene a partir de ella de relacionarse con lo bello. Pero tiene además otras funciones: servir de fuente de reconocimiento de la realidad en que se vive y generar mundos posibles. Este trabajo de investigación es una demostración de que lo aquí planteado es posible y que además puede ser placentero.

\section{Referencias}

Cárdenas Páez, A. (2004), Elementos para una pedagogía de la literatura, Bogotá, Universidad Pedagógica Nacional.

“Entrevista a Jorge Franco" (2004, noviembre), en Revista Rabo de ají [en línea], disponible en http://www. jorge-franco.com, recuperado: 4 de abril del 2011.

Franco Ramos, J. (1999), Rosario Tijeras, Madrid, Plaza \& Janés.

Ricoeur, P. (1995), Tiempo y narración, México, Siglo XXI.

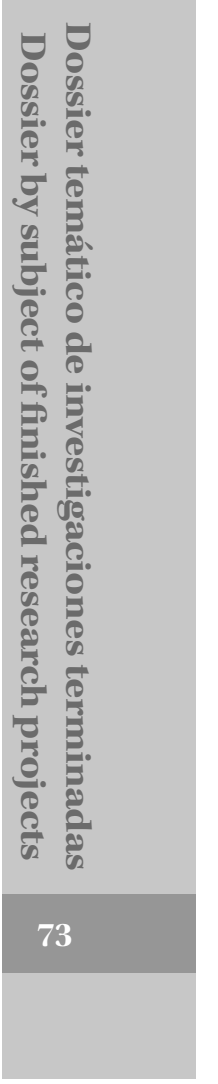

Revista Rastros Rostros - Volumen 13, Número 25 - enero-junio 2011 